Analytical Methods

\title{
Determination of mercury in rice by MSFIA and cold vapour atomic fluorescence spectrometry
}

\author{
Douglas G. da Silva ${ }^{\mathrm{a}, \mathrm{b}}$, Lindomar A. Portugal ${ }^{\mathrm{a}, \mathrm{b}}$, Antonio M. Serra ${ }^{\mathrm{a}}$, Sergio L.C. Ferreira ${ }^{\mathrm{b}, *}$, Victor Cerdà ${ }^{\mathrm{a}}$ \\ ${ }^{a}$ Group of Analytical Chemistry, Automation and Environment, Department of Chemistry, University of the Balearic Islands, E-07122, Palma de Mallorca, Spain \\ ${ }^{\mathrm{b}}$ Universidade Federal da Bahia, Instituto de Química, Grupo de Pesquisa em Química e Quimiometria, Salvador, Bahia 40170-290, Brasil
}

\section{A R T I C L E I N F O}

\section{Article history:}

Received 17 July 2012

Received in revised form 23 August 2012

Accepted 18 October 2012

Available online 26 October 2012

\section{Keywords:}

Mercury

Atomic fluorescence spectrometry

Multisyringe

Rice

\begin{abstract}
A B S T R A C T
In the present paper the use of a MSFIA system for determination of mercury in rice by cold vapour atomic fluorescence spectrometry (CV AFS) is proposed. The sample digestion is performed in a microwave oven using nitric acid and hydrogen peroxide. The experimental conditions for vapour generation were determined using a full two-level factorial design involving the following factors: nitric acid and tin chloride concentrations and sample flow rate. Employing the conditions optimised, the method allows the determination of mercury using the external calibration technique with aqueous standards. The reached limits of detection and quantification were 0.48 and $1.61 \mathrm{ng} \mathrm{g}^{-1}$ respectively, and the precision (as relative standard deviation) was $3.28 \%$ and $1.56 \%$ for rice samples with a mercury content of 3.63 and $5.81 \mathrm{ng} \mathrm{g}^{-1}$, respectively. The method accuracy was confirmed analysing a certified reference material of rice flour furnished by National Institute of Standard and Technology. The interference of nitrous acid and nitrous oxides are removed using potassium dichromate. The method was applied to mercury determination in twelve rice samples acquired in Palma de Mallorca (Spain) between the months of January and April of 2012. The mercury content found varied from 2.15 to $7.25 \mathrm{ng} \mathrm{g}^{-1}$. These results agree with those reported by others authors.
\end{abstract}

(c) 2012 Elsevier Ltd. All rights reserved.

\section{Introduction}

Rice is one of the foods most consumed in the world. Like any plant food, it contains contaminants from soil, fertilisers and other supplies. Thus, quality control of this food is of great importance and, methods for determination and speciation of toxic elements in rice samples are always required (Abbasi, Khodarahmiyan, \& Abbasi 2011; Da Silva et al., 2011; Huang, Fecher, Ilgen, Hu, \& Yang 2012; Raber et al., 2012; Xiang et al., 2012).

Mercury is a toxic element that has accumulative and persistent nature in the environment and biota. Its main form of contamination for humans comes from foods (Tuzen \& Soylak, 2005; Tuzen, Karaman, Citak, \& Soylak, 2009). This way, considering that rice is one of the major foods in the human diets; many studies in rice have been carried out. Mercury was determined in rice employing cold vapour atomic fluorescence spectrometry (CV AFS). The sample digestion was performed using microwave radiation (Mou, Chen, Zhu, \& Chen 2004). Another method was also performed for the determination of total mercury in rice employing CV AFS as analytical technique. The concentrations of mercury in the 24 samples from different origin ranged between 1.3 and $7.8 \mathrm{ng} \mathrm{g}^{-1}$

\footnotetext{
* Corresponding author. Tel./fax: 557132355166.

E-mail address: slcf@ufba.br (S.L.C. Ferreira).
}

(Da Silva, Paim, Pimentel, Cervera, \& de la Guardia 2010). Qian et al. 2010 performed a survey of the levels of potentially toxic elements such as cadmium, lead, mercury and arsenic in milled rice sold on the Chinese market in period of 2005-2008. The mean level found for mercury was $5.8 \mathrm{ng} \mathrm{g}^{-1}$. Several studies on the bioaccumulation process and quantification of methylmercury and inorganic mercury in rice grain have been developed (Meng et al., 2011; Qiu, Feng, Meng, \& Wang 2012; Rothenberg et al., 2011). Another research showed that rice grain is an intensive bioaccumulator of methylmercury, but not of inorganic mercury, which may be trapped by the roots (Zhang, Feng, Larssen, Shang, \& Li 2010). A direct method for the determination of mercury in rice was proposed using slurry sampling and cold vapour atomic absorption spectrometry (CV AAS). Brazilian samples were analysed and the mercury content varied from 4.10 to $13.72 \mathrm{ng} \mathrm{g}^{-1}$ (Silva, da Silva, Leao, Matos, \& Ferreira 2012).

Currently, the atomic fluorescence spectrometry coupled with the cold vapour technique (CV AFS) constitutes one of the best options for the determination of trace amounts of mercury, due to the low cost of the spectrometer and the low limits of detection that can be reached (Sanchez Rodas, Corns, Chen, \& Stockwell 2010). A method for total and inorganic mercury determination in biodiesel was proposed using also CV AFS. The experimental conditions were performed using multivariate optimization techniques (Aranda, Pacheco, Olsina, Martinez, \& Gil 2009). 
Multivariate techniques have been often employed for optimization of analytical methods. Between these, two-level factorial design is used for preliminary evaluation of the experimental factors (Dos Santos et al., 2005; Lemos, Santos, dos Santos, Vieira, \& Novaes 2007; Tarley, dos Santos, dos Santos, Arruda, \& Ferreira 2004). The curvature test is an alternative experiment of the factorial design, which allows evaluating the chemometric response in the region of the central point of the experimental dominions of the studied factors (Ferreira et al., 2011; Massart et al., 1997).

In the present paper a MSFIA system coupled to cold vapour atomic fluorescence spectrometry has been proposed for determination of mercury in rice. The optimization of the experimental conditions has been performed using two-level full factorial design.

\section{Experimental}

\subsection{Reagents}

All solutions and standards were prepared using deionized water obtained from a Milli-Q system (Millipore, Bedford, USA) with a specific resistivity of $18 \mathrm{M} \Omega-\mathrm{cm}$. All reagents were of analytical grade. Nitric acid solutions were prepared via appropriate dilutions from concentrated nitric acid (Merck, Darmstadt, Germany). The working standards were prepared immediately before use by serial dilution from a $1.000 \mathrm{mg} \mathrm{L}^{-1}$ mercury stock solution in $0.05 \%$ nitric acid. The blanks used for the determination of the limits of detection and quantification were $0.05 \%(\mathrm{v} / \mathrm{v})$ nitric acid solutions.

A $1 \%(\mathrm{~m} / \mathrm{v})$ tin chloride solution was prepared daily in $1 \%(\mathrm{~m} / \mathrm{v})$ $\mathrm{HCl}$ dissolving the required amount of $\mathrm{SnCl}_{2} \cdot 2 \mathrm{H}_{2} \mathrm{O}$ purchased from Merck (pro analysis, maximum $0.000001 \% \mathrm{Hg}$ ).

All solutions were made with deionised water purified by a Millipore equipment. All glassware used for preparing dissolutions was soaked in $10 \%(\mathrm{v} / \mathrm{v})$ nitric acid solution and then rinsed with Millipore water.

Dichromate potassium solution $\left(\mathrm{K}_{2} \mathrm{Cr}_{2} \mathrm{O}_{7}\right) 2000 \mathrm{mg} \mathrm{L}^{-1}$ from Panreac reagent (Barcelona, Spain) was used in the preparation of samples and standards.

The accuracy of the method was evaluated using a certified reference material of rice flour (unpolished) and high mercury level, provided by the National Institute of Standard and Technology (NIST), Gaithersburg, MD, USA.

\subsection{Reagent purification}

In order to obtain a lower blank signal, elimination of mercury traces from the carrier and reagents was necessary. The reducing solution was purified with a stream of nitrogen for $30 \mathrm{~min}$ with constant stirring (Reis, Ródenas, Sancenón, Morales, \& de la Guardia 2003).

To purify the carrier solution, a spatula tip of $\mathrm{SnCl}_{2} \cdot 2 \mathrm{H}_{2} \mathrm{O}$ was added and then purged with a stream of nitrogen with constant stirring for $30 \mathrm{~min}$.

\subsection{Samples}

Twelve commercial rice samples were acquired in supermarkets between the months of January and April of 2012, in Palma de Mallorca, Spain. After acquiring the rice, samples were packaged in polypropylene bottles previously decontaminated with nitric acid $10 \%(\mathrm{v} / \mathrm{v})$ for $24 \mathrm{~h}$, and washed with ultrapure water for elimination of interferences metals.

\subsection{Sample preparation using a microwave oven}

The digestion was performed on a $0.50 \mathrm{~g}$ sample with an oxidant mixture composed of $2.0 \mathrm{~mL}$ of concentrated nitric acid, $1.0 \mathrm{~mL}$ of hydrogen peroxide, and $5.0 \mathrm{~mL}$ of ultrapure water. The microwave oven was programmed to heat the sample in seven steps at a pressure of 45 bar, as shown in Table 1 . In the seventh step, the system was cooled for 40 min using forced ventilation. After digestion, the solution presented completely clear. The samples and the blank solutions were then transferred to a plastic flask, and made up to $25 \mathrm{~mL}$ with $8 \%\left(\mathrm{v} / \mathrm{v}\right.$ ) of $\mathrm{HNO}_{3}$. In order to eliminate possible interferences caused by nitrogen oxides, they were eliminated by addition of $100 \mu \mathrm{L} \mathrm{K}_{2} \mathrm{Cr}_{2} \mathrm{O}_{7} 2000 \mathrm{mg} \mathrm{L}^{-1}$ (Da Silva et al., 2010). This procedure was performed in triplicate for each sample that was analysed.

\subsection{Apparatus}

A mercury atomic fluorescence spectrophotometer (P.S. Analytical model 10.023, Orpington, UK) was employed as detector. This spectrometer presents four internal gains and an external fine gain, which allows working on a large concentration range.

The main device is a multisyringe burette module with programmable speed (Multiburette 4S, Crison, Alella, Barcelona). In the proposed system, only two syringes were used (5 and $2.5 \mathrm{~mL}$ ). The multisyringe was equipped with an additional independent solenoid valve (Takasago Electric, Nagoya, Japan). When the valve is used a solenoid protection system (Sciware, Palma de Mallorca, Spain) is required for minimizing heat generation in order to prolong the lifetime of the solenoid valve. The proposed system is shown in Fig. 1.

The argon gas serves as a shield gas, creating a containment wall for the sample in the detection cell, thus avoiding the dispersion of same.

The frequency analytical method is thirty injections per hour, allowing an injection every two minutes.

The manifold for the sample and reagents treatment was built from $1.5 \mathrm{~mm}$ i.d. to $0.8 \mathrm{~mm}$ i.d. PTFE tubing. The $1.5 \mathrm{~mm}$ i.d. tubing was used for reagents pick up, sample coil, spray-generation coil and gas-liquid separator removal tubing. At the same time a sample and reagent mixer was built with $0.8 \mathrm{~mm}$ i.d. tubing. A mixing tee was used to allow gas-liquid mixing and connexion with the spray-generation coil.

A gas-liquid separator from PerkinElmer, model B0507959, was selected. The selection was based on a study of different kinds of liquid separators (Brindle \& Zheng, 1996). An exchangeable PTFE membrane (25 mm diameter, $1 \mu \mathrm{m}$, Schleicher and Schuell, Dassel, Germany) placed in the screw cap of the separator prevents liquid from being carried into the detector cell. The removal of liquid excess from the gas-liquid separators was controlled with a solenoid micro-pump (Biochem Valve Inc., Boonton, NJ, USA).

The solenoid micro-pump was computer controlled through a module (Sciware, Palma de Mallorca), constituted by an I/O digital

Table 1

Microwave heating program for sample digestion.

\begin{tabular}{llll}
\hline Step & Time $(\mathrm{min})$ & Power $(\mathrm{W})$ & $\mathrm{T}\left({ }^{\circ} \mathrm{C}\right)$ \\
\hline 1 & 5 & 800 & 80 \\
2 & 2 & 800 & 80 \\
3 & 4 & 900 & 120 \\
4 & 2 & 900 & 120 \\
5 & 10 & 1000 & 180 \\
6 & 10 & 1000 & 180 \\
Ventilation & 40 & - & - \\
\hline
\end{tabular}




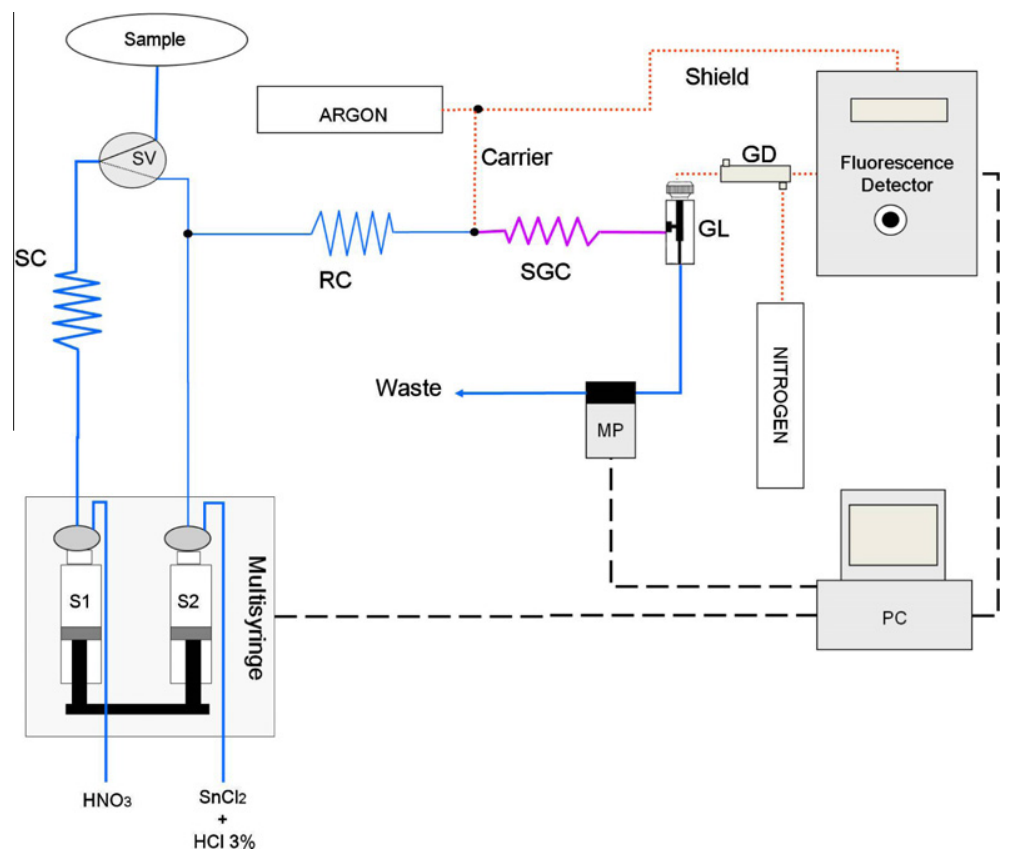

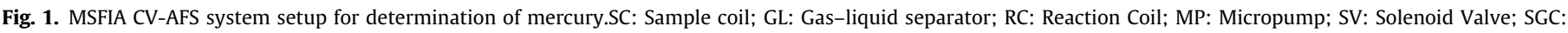
Spray generator coil; PC: Personal computer; GD: Permapure gas dryer.

interface card, eight digital relay output channels and an internal $12 \mathrm{~V}$ power source, which was required to activate the solenoid micro-pumps. This module was connected to a PC through an RS485/RS232 interface.

A gas-dryer unit from Perma Pure (Toms River, NJ, USA) was used. The water moves through the membrane wall and evaporates into the surrounding air or gas.

System control, data acquisition and processing were performed using the Autoanalysis 5.0 software package Sciware, Palma de Mallorca (Becerra, Cladera, \& Cerdà 1999).

\subsection{General procedure}

For sample pick-up, an extra three-way solenoid valve (SV) is connected though a holding coil to syringe S1. Syringe S1 dispenses the sample with $8 \%(\mathrm{v} / \mathrm{v})$ nitric acid solution. Syringe S2 is used to dispense the reducing solution. In order to attain a good reaction efficiency, the flow is stopped in the reaction coil (RC) for $30 \mathrm{~s}$. This stop-flow procedure provides two advantages. First dispersion ceases while chemical reaction continues, and second the consumption of solutions and waste generation are much reduced (Ruzicka, 1992).

Then the mixture is impelled with the carrier to a three-way connector fitting, where the mixture is merged with an argon continuous stream. The generated spray allows an optimal separation of elemental mercury from the liquid phase. The gas-liquid mixture is separated in a gas-liquid separator. Gas phase, which contains elemental mercury, comes out of the gas-liquid separator through a PTFE membrane to the mercury detector. Carrier gas humidity is removed by a Perma Pure device preventing the entrance of water vapour into the detection cell and its interference by quenching (Freeman, McEwan, Claridge, \& Phillips L.F., 1970). Liquid phase is removed by means of a software controlled micropump (MP) in order to keep a constant liquid volume into the gasliquid separator. Analytical parameters characteristic of the system MSFIA CV-AFS are shown in Table 2.
Table 2

Characteristic parameters of the system MSFIA-CV-AFS.

\begin{tabular}{ll}
\hline Flow rate & \\
\hline Pump S1: Sample and blank & $3.0 \mathrm{~mL} \mathrm{~min}^{-1}$ \\
Pump S2: $\mathrm{SnCl}_{2}$ & $1.5 \mathrm{~mL} \mathrm{~min}^{-1}$ \\
Volume & \\
Sample & $0.500 \mathrm{~mL}$ injection \\
$\mathrm{SnCl}_{2}$ & $0.300 \mathrm{~mL}$ injection \\
Detector of mercury & \\
Source & Mercury lamp \\
Analytical line & $254.0 \mathrm{~nm}$ \\
Gain & 1000 \\
Current of argon gas & $110 \mathrm{~mL} \mathrm{~min}^{-1}$ \\
Current of nitrogen gas & $300 \mathrm{~mL} \mathrm{~min}^{-1}$ \\
\hline
\end{tabular}

\section{Results and discussions}

3.1. Optimization of the experimental conditions for quantification of mercury by MSFIA CV AFS

Firstly a two-level factorial design was performed involving the followings factors: nitric acid concentration, tin(II) chloride concentration and sample flow rate, having as chemometric response fluorescence intensity. The Table 3 shows the coded and real values of the factors and the results of the experiments as fluorescence intensity.

The effects of the three factors on the vapour generation were calculated as (Bruns, Scarminio, \& Neto, 2006). The values found were:

$$
\begin{aligned}
& \text { Effect }_{\left[\mathrm{HNO}_{3}\right]}=6.97 \pm 0.31 \\
& \text { Effect }_{\left[\mathrm{SnCl}_{2}\right]}=8.90 \pm 0.31 \\
& \text { Effect }_{\text {sample flow rate }}=3.00 \pm 0.31
\end{aligned}
$$

These data demonstrated that all these three factors are statistically significant on the vapour generation for the experimental conditions established. 
Table 3

Full two-level factorial design-optimization of the procedure for CV AFS.

\begin{tabular}{lcccc}
\hline Experiment & {$\left[\mathrm{HNO}_{3}\right](\%)$} & {$\left[\mathrm{SnCl}_{2}\right](\%)$} & Sample flow rate $\left(\mathrm{mL} \mathrm{min}^{-1}\right)$ & Fluorescence intensity \\
\hline 1 & $-(6.0)$ & $-(1.0)$ & $-(1.0)$ & 23.60 \\
2 & $+(10.0)$ & $-(1.0)$ & $-(1.0)$ & 24.15 \\
3 & $-(6.0)$ & $+(5.0)$ & $-(1.0)$ & 29.09 \\
4 & $+(10.0)$ & $+(5.0)$ & $+(1.0)$ & 41.62 \\
5 & $-(6.0)$ & $-(1.0)$ & $+(5.0)$ & 22.81 \\
6 & $+(10.0)$ & $+(5.0)$ & $+(5.0)$ & 36.11 \\
7 & $-(6.0)$ & $+(5.0)$ & $+(5.0)$ & 35.02 \\
8 & $+(10.0)$ & $0(3.0)$ & $0(3.0)$ & 36.53 \\
$\mathrm{CP}$ & $0(8.0)$ & $0(3.0)$ & $0(3.0)$ & 35.90 \\
$\mathrm{CP}$ & $0(8.0)$ & $0(3.0)$ & $0(3.0)$ & 35.70 \\
$\mathrm{CP}$ & $0(8.0)$ & & 35.75 \\
\hline
\end{tabular}

$\mathrm{CP}$, central point.

Table 4

Evaluation of the accuracy of the method using addition/recovery test.

\begin{tabular}{lllll}
\hline Sample & $\begin{array}{l}\text { Mercury } \\
\text { content }\left(\mathrm{ng} \mathrm{g}^{-1}\right)\end{array}$ & $\begin{array}{l}\text { Mercury } \\
\text { added }\left(\mathrm{ng} \mathrm{g}^{-1}\right)\end{array}$ & $\begin{array}{l}\text { Mercury } \\
\text { achieved }\left(\mathrm{ng} \mathrm{g}^{-1}\right)\end{array}$ & $\begin{array}{l}\text { Recovery } \\
(\%)\end{array}$ \\
\hline 1 & $3.63 \pm 0.27$ & 4.00 & $7.38 \pm 0.57$ & 96 \\
& & 6.00 & $9.48 \pm 0.23$ & 98 \\
2 & $6.41 \pm 0.43$ & 4.00 & $10.27 \pm 0.21$ & 98 \\
& & 6.00 & $12.19 \pm 0.18$ & 98 \\
3 & $2.04 \pm 018$ & 4.00 & $5.90 \pm 0.16$ & 97 \\
& & 6.00 & $7.96 \pm 0.21$ & 99 \\
\hline
\end{tabular}

The curvature test was also applied in the results of the factorial design, being the curvature calculated using the equation: Curvature $=R_{\mathrm{FD}}-R_{\mathrm{CP}}$, where $R_{\mathrm{FD}}$ is the average of the responses obtained from experiments specified by the factorial design, and $R_{C P}$ is the average of the responses obtained for the central point. An analysis of the results, being $R_{\mathrm{FD}}=(31.12)$ and $R_{\mathrm{Cp}}=$ (35.78), shows a negative curvature. It means that there is a maximum condition of fluorescence intensity close to central point of the experimental dominions established in the factorial design.

Considering the result of the curvature test the experimental conditions established for determination of mercury by MSFIA CV AFS were: sample flow rate of $3.0 \mathrm{~mL} \mathrm{~min}^{-1}$, nitric acid concentration of $8.0 \%(\mathrm{v} / \mathrm{v})$ and tin(II) chloride concentration of $3.0 \%(\mathrm{~m} / \mathrm{v})$.

\subsection{Validation of the method proposed}

Firstly the matrix effect was investigated using the analyte addition technique in order to choose the calibration technique of the method. Mercury solutions with end concentrations of 0 , $0.10 ; 0.50 ; 1.00 ; 1.50 ; 2.00 \mu \mathrm{g} \mathrm{L}^{-1}$ were added to a solution of rice sample, which was digested by microwave radiation using the procedure described in experimental part. In this experiment, the slope of the analytical curve (expressed at the 95\% confidence level) was $(35.98 \pm 0.94)$. An external calibration curve was determined using aqueous standards at the same concentrations and, the slope obtained was $(35.29 \pm 1.62)$. These results evidenced that the external calibration technique can be used for the quantification of mercury in rice samples, being that the analytical curve is linear up to $10.0 \mu \mathrm{g} \mathrm{L}^{-1}$. The limits of detection and quantification were determined as IUPAC recommendation (IUPAC, 1978). The values achieved for a digested rice mass of $0.50 \mathrm{~g}$ were 0.48 and $1.61 \mathrm{ng} \mathrm{g}^{-1}$, respectively. The value obtained for the limit of detection is lower than others found as $0.90 \mathrm{ng} \mathrm{g}^{-1}$ (Da Silva et al., 2010) and $0.95 \mathrm{ng} \mathrm{g}^{-1}$ (Silva et al., 2012). The precision expressed as relative standard deviation was evaluated for two rice samples with mercury content of 3.63 and $5.81 \mathrm{ng} \mathrm{g}^{-1}$. The results found were $3.28 \%$ and $1.56 \%$, respectively for $n=10$. The accuracy of the method was confirmed using the NIST-SRM 1568a rice flour certified
Table 5

Determination of mercury in rice samples $(n=3)$.

\begin{tabular}{lll}
\hline Sample & Type of rice & Mercury content ${ }^{*}\left(\mathrm{ng} \mathrm{g}^{-1}\right)$ \\
\hline 1 & $\mathrm{P}$ & $4.81 \pm 0.52$ \\
2 & $\mathrm{P}$ & $3.63 \pm 0.27$ \\
3 & $\mathrm{P}$ & $5.14 \pm 0.45$ \\
4 & $\mathrm{~W}$ & $4.65 \pm 0.31$ \\
5 & $\mathrm{~W}$ & $6.41 \pm 0.43$ \\
6 & $\mathrm{P}$ & $2.92 \pm 0.14$ \\
7 & $\mathrm{P}$ & $2.15 \pm 0.16$ \\
8 & $\mathrm{~W}$ & $3.94 \pm 0.08$ \\
9 & $\mathrm{~W}$ & $7.25 \pm 0.36$ \\
10 & $\mathrm{~W}$ & $2.76 \pm 0.18$ \\
11 & $\mathrm{P}$ & $4.30 \pm 0.22$ \\
12 & $\mathrm{P}$ & $5.82 \pm 0.11$ \\
\hline
\end{tabular}

$\mathrm{P}$, parboiled rice; $\mathrm{W}$, white rice.

* Results as interval confidence at 95\% level.

reference material. The mercury concentration achieved of $\left(5.3 \pm 0.2 \mathrm{ng} \mathrm{g}^{-1}\right)$ was found in agreement with the certified value of $\left(5.8 \pm 0.5 \mathrm{ng} \mathrm{g}^{-1}\right)$. Tests of addition/recovery were also performed using three real rice samples. Additions of 4.0 and $6.0 \mathrm{ng}$ per gram of rice sample resulted in recoveries varying from $96 \%$ to $99 \%$ as can be seen in Table 4 .

\subsection{Application - determination of mercury in rice samples}

The method proposed was used for the quantification of mercury in twelve real samples of rice purchased in supermarkets from Palma de Mallorca, Spain. All the samples were digested by microwave radiation. The mercury content varied from 2.15 to $7.86 \mathrm{ng} \mathrm{g}^{-1}$, with an average value of $4.48 \mathrm{ng} \mathrm{g}^{-1}$. The results obtained can be seen in Table 5 . The results found agreed with those obtained by other authors (Da Silva et al., 2010; Qian et al., 2010; Silva et al., 2012).

\section{Conclusions}

The stannous chloride was chosen as reducing agent because is cheaper than sodium tetrahydroborate. Furthermore, the sensitivity obtained is perfectly compatible for the determination of mercury in rice.

The linear model obtained by factorial design showed lack of fit; however this data is compatible considering that the curvature is significant.

The proposed method allows the determination of mercury using the external calibration technique with aqueous standards, with precision and accuracy. 
The concentrations of mercury found in the samples analysed agreed with the results achieved by other authors in other countries.

\section{References}

Abbasi, S., Khodarahmiyan, K., \& Abbasi, F. (2011). Simultaneous determination of ultra trace amounts of lead and cadmium in food samples by adsorptive stripping voltammetry. Food chemistry, 128, 254-257.

Aranda, P. R., Pacheco, P. H., Olsina, R. A., Martinez, L. D., \& Gil, R. A. (2009). Total and inorganic mercury determination in biodiesel by emulsion sample introduction and FI-CV-AFS after multivariate optimization. Journal of Analytical Atomic Spectrometry, 24, 1441-1445.

Becerra, E., Cladera, A., \& Cerdà, V. (1999). Design of a very versatile software program for automating analytical methods. Laboratory robotics and automation, $11,131-140$.

Brindle, I. D., \& Zheng, S. (1996). A comparison of gas-liquid separators for the determination of mercury by cold-vapour sequential injection atomic absorption spectrometry. Spectrochimica Acta B, 51, 1777-1780.

Bruns, R. E., Scarminio, I. S., \& Neto, B. B. (2006). Statistical design-chemometrics. Amsterdam: Elsevier.

Da Silva, M. J., Paim, A. P. S., Pimentel, M. F., Cervera, M. L., \& de la Guardia, M. (2010). Determination of mercury in rice by cold vapor atomic fluorescence spectrometry after microwave-assisted digestion. Analytica Chimica Acta, 667, 43-48.

Da Silva, D. G., Junior, M. M. S., Silva, L. O. B., Portugal, L. A., Matos, G. D., \& Ferreira, S. L. C. (2011). Determination of cadmium in rice by electrothermal atomic absorption spectrometry using aluminum as permanent modifier. Analytical Methods, 3, 2495-2500.

Dos Santos, W. N. L., Dias, F. D. S., Fernandes, M. S., Reboucas, M. V., Vale, M. G. R. Welz, B., et al. (2005). Application of multivariate technique in method development for the direct determination of copper in petroleum condensate using graphite furnace atomic absorption spectrometry. Journal of Analytical Atomic Spectrometry, 20, 127-129.

Ferreira, S. L. C., Macedo, S. M., dos Santos, D. C., de Jesus, R. M., dos Santos, W. N. L., Queiroz, A. F. S., et al. (2011). Speciation analysis of inorganic antimony in airborne particulate matter employing slurry sampling and HG QT AAS. Journal of Analytical Atomic Spectrometry, 26, 1887-1891.

Freeman, C. G., McEwan, M. J., Claridge, R. F. C., \& Phillips, L. F. (1970). Mercurysensitized luminescence of $\mathrm{H}_{2} \mathrm{O}$ and $\mathrm{D}_{2} \mathrm{O}$. Transactions of the faraday society, 66 , 2974.

Huang, J. H., Fecher, P., Ilgen, G., Hu, K. N., \& Yang, J. (2012). Speciation of arsenite and arsenate in rice grain - Verification of nitric acid based extraction method and mass sample survey. Food chemistry, 130, 453-459.

IUPAC and Analytical Chemistry Division. (1978). Spectrochimica Acta Part B, 33, 242

Lemos, V. A., Santos, M. S., dos Santos, M. J. S., Vieira, D. R., \& Novaes, C. G. (2007). Determination of copper in water samples by atomic absorption spectrometry after cloud point extraction. Microchimica Acta, 157, 215-222.
Massart, D. L., Vandeginste, B. G. M., Buydens, L. M. C., Jong, S., Lewi, P. J., \& SmeyersVerbeke, J. (1997). Handbook of chemometrics and qualimetrics: Part A. Amsterdam: Elsevier.

Meng, B., Feng, X. B., Qiu, G. L., Liang, P., Li, P., Chen, C. X., et al. (2011). The process of methylmercury accumulation in rice (Oryza sativa L.). Environmental science $\mathcal{E}$ Technology, 45, 2711-2717.

Mou, R. X., Chen, M. X., Zhu, Z. W., \& Chen, N. (2004). Determination of trace mercury in rice by microwave digestion-hydride generation-atomic fluorescence spectrometry. Spectroscopy and Spectral Analysis, 24, 236-237.

Qian, Y. Z., Chen, C., Zhang, Q., Li, Y., Chen, Z. J., \& Li, M. (2010). Concentrations of cadmium, lead mercury and arsenic in Chinese market milled rice and associated population health risk. Food Control, 21, 1757-1763.

Qiu, G. L., Feng, X. B., Meng, B., \& Wang, X. (2012). Methylmercury in rice (Oryza sativa L.) grown from the Xunyang $\mathrm{Hg}$ mining area, Shaanxi province, northwestern China. Pure and Applied Chemistry, 84, 281-289.

Raber, G., Stock, N., Hanel, P., Murko, M., Navratilova, J., \& Francesconi, K. A. (2012). An improved HPLC-ICPMS method for determining inorganic arsenic in food: Application to rice, wheat and tuna fish. Food chemistry, 134, 524-532.

Reis, B. F., Ródenas, E., Sancenón, J., Morales, A., \& de la Guardia, M. (2003). Multicommutation cold vapour atomic fluorescence determination of $\mathrm{Hg}$ in water. Talanta, 60, 809-819.

Rothenberg, S. E., Feng, X. B., Dong, B., Shang, L. H., Yin, R. S., \& Yuan, X. B. (2011). The process of methylmercury accumulation in rice (Oryza sativa L.). Environmental Pollution, 159, 1283-1289.

Ruzicka, J. (1992). The 2nd coming of flow-injection analysis. Analytica Chimica Acta, $261,3-10$.

Sanchez Rodas, D., Corns, W. T., Chen, B., \& Stockwell, P. B. (2010). Atomic fluorescence spectrometry: A suitable detection technique in speciation studies for arsenic, selenium, antimony and mercury. Journal of Analytical Atomic Spectrometry, 25, 933-946.

Silva, L. O. B., da Silva, D. G., Leao, D. J., Matos, G. D., \& Ferreira, S. L. C. (2012). Slurry sampling for the determination of mercury in rice using cold vapor atomic absorption spectrometry. Food Analytical Methods, 5, 1289-1295.

Tarley, C. R. T., dos Santos, W. N. L., dos Santos, C. M., Arruda, M. A. Z., \& Ferreira, S. L. C. (2004). Factorial design and doehlert matrix in optimization of flow system for preconcentration of copper on polyurethane foam loaded with 4(2-pyridylazo)-resorcinol. Analytical Letters, 37, 1437-1455.

Tuzen, M., Karaman, I., Citak, D., \& Soylak, M. (2009). Mercury(II) and methyl mercury determinations in water and fish samples by using solid phase extraction and cold vapour atomic absorption spectrometry combination. Food and Chemical Toxicology, 47, 1648-1652.

Tuzen, M., \& Soylak, M. (2005). Mercury contamination in mushroom samples from Tokat-Turkey. Bulletin of Environmental Contamination and Toxicology, 74, 968-972.

Xiang, G. Q., Wen, S. P., Wu, X. Y., Jiang, X. M., He, L. J., \& Liu, Y. L. (2012). Selective cloud point extraction for the determination of cadmium in food samples by flame atomic absorption spectrometry. Food chemistry, 132, 532-536.

Zhang, H., Feng, X., Larssen, T., Shang, L., \& Li, P. (2010). Bioaccumulation of methylmercury versus inorganic mercury in rice (Oryza sativa L.) grain. Environmental Science and Technology, 44, 4499-4504. 